\title{
A NEW FORM OF HILBERT INTEGRAL INEQUALITY
}

\author{
TSEREndorJ BATBOLd AND LAith E. AZAR
}

Abstract. In this paper by estimating the triple integral $\int_{0}^{\infty} \int_{0}^{\infty} \int_{0}^{\infty} \frac{f(x, y) g(z)}{(x+y+z)^{\lambda}} d x d y d z$, we introduce a new form of the Hilbert inequality for three variables with a best constant factor. The reverse form and some equivalent forms are also considered.

Mathematics subject classification (2010): 26D15, 47A07.

Keywords and phrases: Hilbert inequality, gamma function, the best possible constant, conjugate exponents.

\section{REFERENCES}

[1] L. E. AZAR, Some Extensions of Hilbert's integral inequality, J. Math. Inequal. 5, 1 (2011), 131-140.

[2] I. BRnetić, M. KRnić AND J. PeČArIĆ, Multiple Hilbert and Hardy-Hilbert inequalities with nonconjugate parameters, Bull. Aust. Math. Soc. 71, 3 (2005), 447-457.

[3] M. T. GARAYEV, M. GÜRDAl AND A. OKUDAN, Hardy-Hilbert's inequality and power inequalities for Berezin numbers of operators, Math. Inequal. Appl. 19, 3 (2016), 883-891.

[4] G. H. Hardy, J. E. Littlewood and G. Polya, Inequalities, Cambridge Univ. Press, London, 1952.

[5] M. KRnić, A refined discrete Hilbert inequality via the Hermite-Hadamard inequality, Comput. Math. Appl. 63, 12 (2012), 1587-1596.

[6] M. Krnić, G. Mingzhe, J. PeČAriĆ And G. Xuemei, On the best constant in Hilbert's inequality, Math. Ineq. and Appl. 8, 2 (2005), 317-329.

[7] M. KRniĆ And J. PeČARIĆ, Extension of Hilbert's inequality, J. Math. Anal. Appl. 324, 1 (2006), $150-160$.

[8] M. Krnić, J. Pečarić, I. Perić And P. Vuković, Recent Advances in Hilbert-type Inequalities, Element, Zagreb, 2012.

[9] M. KRnić, J. PeČARIĆ And P. Vuković, On some higher-dimensional Hilbert's and HardyHilbert's integral inequalities with parameters, Math. Inequal. Appl. 11, 4 (2008), 701-716.

[10] G. Mingzhe And B. YAng, On the extended Hilbert's inequality, Proc. Amer. Math. Soc. 126, 3 (1998), 751-759.

[11] D. S. MitrinOvić, J. PeČARIĆ AND A. M. FinK, Classical and new inequalities in analysis, Kluwer Academic, Publishers, Dordrecht/Boston/London, 1993.

[12] B. YAng, On a new multiple extension of Hilbert's integral inequality, J. Inequal. Pure Appl. Math. 6, 2 (2005), 1-8.

[13] B. YANG, The norm of operator and Hilbert-type inequalities, Science press, Beijing, 2009.

[14] B. YANG AND T. M. RASSIAS, On the way of weight coefficients and research for the Hilbert-type inequalities, Math. Inequal. Appl. 6, 4 (2003), 625-658. 